\title{
The Attitude of the Academic Community towards Distance Learning: A Lesson from a National Lockdown
}

\author{
Marta Migocka-Patrzałek, Magda Dubińska-Magiera, Dawid Krysiński and Stefan Nowicki \\ University of Wrocław, Poland \\ marta.migocka-patrzalek@uwr.edu.pl
}

magda.dubinska-magiera@uwr.edu.pl

dawid.krysinski@uwr.edu.pl

stefan.nowicki@uwr.edu.pl

Marta Migocka-Patrzałek (ORCID 0000-0003-0077-7779)

Magda Dubińska-Magiera (ORCID 0000-0003-2725-3924)

DawidKrysiński (ORCID 00000-0003-3568-5532)

Stefan Nowicki (ORCID 0000-0003-2967-8483)

All authors contributed equally to this work

\begin{abstract}
The number of online courses conducted at universities has been growing steadily worldwide. The demand for this form of education has jumped sharply in the 2019/2020 academic year as a consequence of the COVID-19 pandemic and the national lockdown. The following study uses the case of University of Wrocław and examines how this unprecedented situation would affect the attitude of members of the academic community toward distance learning. The examination, based on quantitative analysis of separated questionnaires distributed among teachers and students, reveals that the previous experience in distance learning strongly correlates with willingness to use it in the future, i.e. after fighting the coronavirus crisis. Thus, the research suggests that the implementation of distance learning may involve the need to put more emphasis on systematic and long-term actions. The results achieved in the study may contribute to improving the ways of implementing distance learning on a large scale in institutions dealing with higher education.
\end{abstract}

Keywords: COVID-19, distance teaching, emergency remote teaching, e-learning, remote teaching

\section{Introduction}

Higher schools and universities provide education to students mainly through traditional activities such as lectures and practical training. However, the tendency to introduce online courses has been growing steadily worldwide (Palvia et al. 2018). The educational experience at the University of Wrocław confirms this tendency. Since the 2016/2017 academic year the number of e-learning courses has been growing about 3-fold every year (according to the Centre of Distance Learning database). The national lockdown and healthprotecting restrictions due to the COVID-19 pandemic introduced all around the world have necessitated profound changes in the way of teaching. Universities, as well as other kinds of schools, are switching to remote teaching. This unique situation, described sometimes as a "great online-learning experiment" (Zimmerman 2020), gave the opportunity for an in-depth analysis of the academic community's attitude towards the advantages and weaknesses of remote teaching both from the teachers' and students' points of view. Both teachers and students were obliged to change their habits and routine and switch to online teaching in a very short period. It is wondering what this experience might mean for future remote education.

Does it introduce a permanent change in the way of teaching or is it only a temporary solution? The following article assumes that the case of the COVID-19 pandemic emergency, when the online teaching is obligatory, will not increase the social acceptance for online courses after fighting the coronavirus crisis. Contrary to this, it is also assumed that the experience in distance learning gained before the COVID-19 pandemic is a factor, which positively influences the teachers' and students' attitudes towards distance learning.

The term "e-learning" means electronic learning and is strongly connected with and dependent on the Internet. E-learning refers to the learning of students which takes place online. This form of education originated in the 1990s (Sinclair, Kable, and Levett-Jones 2015). E-learning can provide many advantages.

Among them, flexible time management, a higher number of students with the opportunity to participate in education due to multiple access, the possibility of reducing the cost of classrooms, and laboratory training (e.g. the cost of reagents, personal protective equipment, etc.) should be mentioned. Distance learning is also a solution to typical infrastructure difficulties. For example, it allows teachers to easily share the content of 
lectures without limitation connected with lecture hall capacity. E-learning is not only a distance learning process but all together could provide real, virtual meetings, individual or collective tutoring, seminars, and more. E-learning could be more involving since it demands higher concentration and intensive individual work from students to solve the problems. At the same time, the remote way of work respects the individual working rhythm and learner abilities to accomplish a given task (Ilie 2019).

One should keep in mind that in the emergency remote teaching situation, the terms "online" and "distance learning" are often used without paying adequate attention toward the exact content of educational courses and ways of providing knowledge. A variety of methodologies such as distance learning, e-learning, blended learning, online learning, mobile learning, and many others, could be distinguished among them. One of the main differences is the student role in online learning. Depending on the methodology they could just listen and read, almost as in traditional teaching, or be more involved in completing problems and answering questions, explore simulations and resources, and/or collaborate with peers ( Means, Bakia, and Murphy 2014; Hodges et al. 2020). Being aware of the differences between the above mentioned terms, due to the clarity of the argumentation and the nature of didactic activities that were undertaken by the studied academic community, as a direct consequence of the COVID-19 pandemic, the authors of this work decided to use the term- "distance learning".

As a benefit of advances in information technology, distance learning can be based on high-performance communication systems that improve students' perception via visualization of different, not-visible processes (Morales-Menendez, Ramírez-Mendoza, and Vallejo Guevara 2019). Distance learning ensures better access to education for people with disabilities. Another advantage of distance learning can be environmental benefits connected with the carbon footprint reduction of distance learning users mostly resulting from limiting their travels to face-to-face meetings (Walsh 2018). In the context of distance learning, the most concern can be raised by the issue of hand-on based laboratories, which are characterized by different specifics and requirements in the form of appropriate infrastructure facilities than lectures or seminars. Among the basic disadvantages of this teaching method are a large amount of work required and limited face-to-face contacts (Arkorful and Abaidoo 2014). There is also a question whether distance learning could effectively replace traditional teaching, which provides many advantages such as a strong impact in the form of direct, efficient teacher feedback in response to students' activity, personal interactions allowing for modifications of the teaching process, adjusting to pupils' knowledge level, and a flexible formula enabling free discussion (Ilie 2019).

Therefore, although distance education could be seen as an alternative to the traditional educational process, the question of whether virtual teaching is more or less effective and accepted by teachers and students is still valid. The Education Endowment Foundation (EEF) reported in 2020 that it is difficult to use distance learning to replace the face-to-face learning interactions between teachers and students. Many research groups have conducted studies about this problem ( Engum, Jeffries, and Fisher 2003; Corter et al. 2011; Brinson 2015; Clark et al. 2020; Marasi, Jones, and Parker et al. 2020). Some have concluded that the students' learning outcome achievements are comparable in the case of both distance and conventional techniques (Corter et al. 2011; Brinson 2015). Distance learning teaching requires a change in the pedagogical style and very careful design of the training process (Ilie 2019). While in the traditional learning all the educational processes including planning, monitoring, and evaluation are maintained by teachers, distance learning also involves the student and can be recognized as a part of socio-emotional development (Volet et al. 2009). As in conventional learning, a teacher also plays an important role in distance learning. As shown in different studies, teachers' involvement and their ability to share knowledge have a huge influence on students' performance and satisfaction (Viegas et al. 2018).

While distance learning has many advantages it is impossible not to mention some of its weaknesses and the associated risks. One of them, procrastination, is linked to time management and defined as the tendency to unreasonably delay the completion of a task. Procrastination is one of the most common behaviors that negatively affect the effectiveness of the teaching process, especially through distance learning. Also, the physical and psychological isolation of distance learning participants is an important problem. Minimizing this risk of the above problems or significantly mitigating their impact requires, among other issues, an appropriate way of teaching, additional student stimulation, and the development of new tools such as webinars to facilitate social interaction and collaborative learning (Croft, Dalton, and Grant 2010; Michinov et al. 2011; Hong, Lee, and Ye 2021; Stebbings et al. 2021). 
Despite its drawbacks and its advantages, distance learning is becoming increasingly important in higher education and is being introduced to the education of students in various fields around the world (Trelease 2016; Walsh 2018; Marasi, Jones, and Parker 2020).

\subsection{Study Design}

The present study was carried out at the University of Wrocław 7 weeks after cancellation of lectures and classes for undergraduate, graduate, post-graduate, and doctoral students, as well as participants of other forms of education, due to the COVID-19 pandemic. During this period emergency distance learning was implemented.

It is worth to note, however, that the pandemic COVID-19 is not the first time during which the University of Wrocław implemented the distance learning. This form of education has been used for 5 years (mostly in the form of e-learning). The number of classes and lectures conducted using this approach was initially small but was steadily increasing. The rapid increase in distance learning interest in the 2019/2020 academic year was dictated by the emergence of the COVID-19 pandemic. A $724 \%$ increase in the number of distance learning courses in the summer semester was observed when compared to the winter semester (Fig. 1). At the University of Wrocław, before and during the lockdown, distance learning has been carried out using an educational platform equipped with Moodle MLS, a free and open-source learning management system. Moreover, the University of Wrocław acquired Microsoft Office 365 Online in the year 2016 with free licenses for students and teachers, and full licenses in the year 2020.

Figure 1: Number of distance learning courses at the University of Wrocław in the years 2016-2020

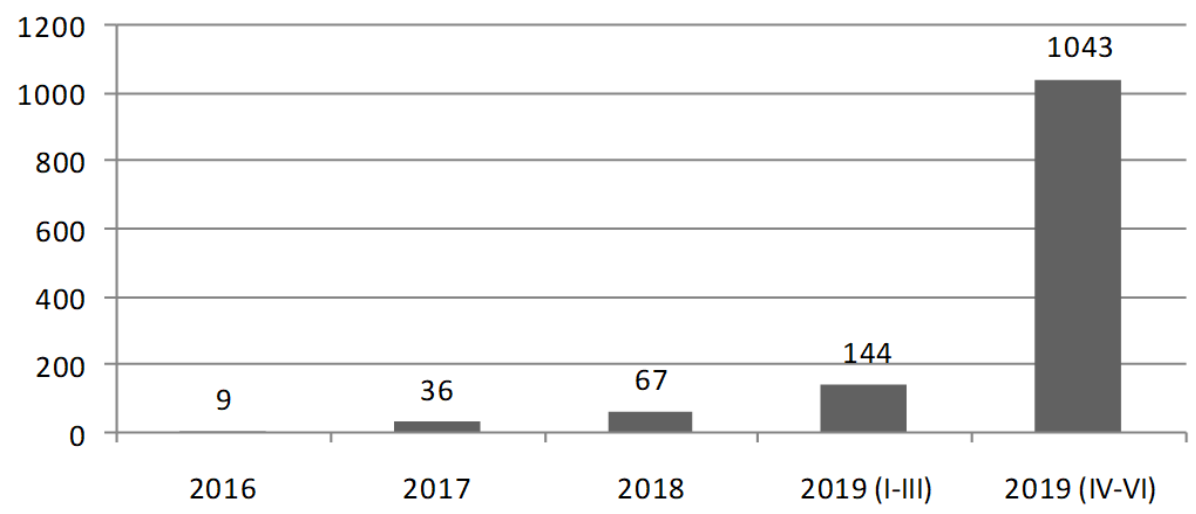

The University of Wrocław has made efforts to improve the qualifications of the academic staff necessary to conduct distance learning including e-learning courses. These efforts included, among others, implementation and execution of training within the project "Good Staff - increasing the competence of the teaching staff of the University of Wrocław to strengthen the quality of education", supported by the EU within the European Social Fund co-financed by the European Union. These workshops, under the name "e-learning in teaching practice" were organized in three editions in the years 2017-2019. The total number of teachers who took part in the training was 60 . This resulted in the implementation of 144 courses containing elements of distance learning before the rapid increase caused by the "emergency remote teaching" due to the COVID-19 pandemic (Fig. 1). The significant number of mentioned courses is a combination of the two methodologies (conventional and distance learning), referred to as "blended learning". This approach is popular and considered as effective since it may enhance students' satisfaction and allow them to acquire knowledge and relevant skills (Engum, Jeffries, and Fisher 2003).

This particular study is based on the survey which was conducted among the academic community (teachers and students) of the University of Wrocław. In the project, a web survey was used due to the extraordinary circumstances significantly limiting opportunities to conduct a traditional survey with face-to-face contact. Research team was allowed to distribute the questionnaire among all students and teachers but did not have an access to personal e-mails due to the data protection regulations. For this reason, a convenience sampling, instead of a random selection of respondents, was used in the study. In total, 278 teachers and 2301 students' answers from humanities and science faculty were taken into account. 
In the study, two separate questionnaires were developed, one for teachers and one for students. Questions included in both questionnaires concerned the experience in using distance learning tools, attitude towards such a method after the COVID-19 pandemic and subjective assessment of advantages and disadvantages of distance learning. Respondents were also asked to express their opinions about the opportunities for wider implementation of distance learning at the University of Wrocław after the COVID-19 pandemic (it was an open question). In addition, teachers answered an additional question about the reasons for which they started to participate in distance learning practices, while students were asked to define their attitude towards distance learning before the COVID-10 pandemic. The content of each questionnaire is presented in the appendix section. It is also important to note that the survey was anonymous and voluntary. The information regarding the place of work (the particular faculty) and the sex was not obligatory as well.

Three detailed hypotheses were proposed and verified in the article. The first one is that the need to take part in distance learning activities during the national lockdown will not have a positive impact on the willingness to use distance learning in the future, i.e. after fighting the coronavirus crisis. The second hypothesis is that the previous experiences with distance learning, gained before the pandemic, strengthen the positive attitude of respondents to distance teaching in the future. The last hypothesis is that the positive attitude to distance teaching in the future is connected not only with a more positive assessment of advantages of distance learning but also with a less critical attitude to its weaknesses.

The two first hypotheses were examined based on three binary logistic regression models - two calculated for teachers and one regarding students. Logistic regression is a commonly used method in which a binary response variable is related to a set of explanatory variables. In this approach, the probability (odds) of the response taking a particular value is modelled based on a combination of values taken by the predictors. The models used in the article concern the identification of factors that affect the respondents' attitudes to distance learning in the future. The design and results of the models are described in Tables 3 and 4, section 3.1.

In the next step, aimed at verifying the third hypothesis, the Mann-Whitney $U$ nonparametric test was used to compare the differences between scores obtained by the four independent categories of respondents: (1) teachers willing to use distance learning after the COVID-19 pandemic, (2) teachers not willing to use distance learning after the COVID-19 pandemic, (3) students willing to use distance learning after the COVID-19 pandemic and (4) students not willing to use distance learning after the COVID-19 pandemic. The MannWhitney $U$ test was chosen because the values were not normally distributed and the categories of respondents did not have the same number of items. The results of the tests are described in Table 7, section 3.2 .

In addition, a chi-square test of independence, which compares two variables in a contingency table, was used to see whether distributions of categorical variables differ from each other. The test was used to provide more detailed results and to compare assessments of single advantages and disadvantages among the four aforementioned categories of respondents (see Tables 8 and 9, section 3.2). In the discussion section, several qualitative opinions of the respondents (collected in the survey) were also taken into account to provide better insight into the respondents' opinions about the future of distance learning at the University of Wrocław.

\section{Research Results}

\subsection{Predictors of positive and negative attitude to distance learning courses in the future}

Identification of factors that affect the respondents' attitudes to distance learning in the future was conducted with the use of logistic regression analysis. All three models included dependent variable based on the question in which respondents were asked about their willingness to use distance learning. The distributions obtained among teachers and students are presented in Table 1. 
Table 1: Distribution of willingness to use distance learning after the COVID-19 pandemic among teachers and students

\begin{tabular}{|l|r|r|r|r|r|}
\hline \multicolumn{2}{|c|}{} & \multicolumn{2}{|c|}{ Category of respondent } & \multirow{2}{*}{ In total } \\
\cline { 3 - 6 } & & \multicolumn{2}{|c|}{ Teacher } & \multicolumn{1}{c|}{ Student } & \\
\hline \multirow{3}{*}{$\begin{array}{l}\text { Willingness to use distant learning in } \\
\text { the future }\end{array}$} & \multirow{2}{*}{ No } & $\mathrm{N}$ & 174 & 1484 & 1658 \\
\cline { 3 - 6 } & & $\%$ & $62.60 \%$ & $64.50 \%$ & $64.30 \%$ \\
\cline { 3 - 6 } & \multirow{2}{*}{ Yes } & $\mathrm{N}$ & 104 & 817 & 921 \\
\cline { 3 - 6 } & & $\%$ & $37.40 \%$ & $35.50 \%$ & $35.70 \%$ \\
\hline \multirow{2}{*}{ In total } & $\mathrm{N}$ & 278 & 2301 & 2579 \\
\cline { 3 - 6 } & & $100.00 \%$ & $100.00 \%$ & $100.00 \%$ \\
\hline
\end{tabular}

The first model calculated for teachers includes three basic elements that were tested as independent variables (predictors) that might influence the attitude towards distance learning in the future: type of department, sex, and reasons for which the teachers started to participate in distance learning practices. The model with all the predictors is significantly better than the constant only model $\left(\chi^{2}=41.321, \mathrm{df}=7\right.$, and $\left.p<.001\right)$. It can be also concluded that the model fits the data $\left(\chi^{2}=3.815, \mathrm{df}=8\right.$, and $\left.\mathrm{p}>.05\right)$.

In the second model regarding the teachers, an additional variable describing a personal experience with distance learning was used, together with type of department, sex, and reasons for which the teachers started to participate in distance learning practices. As in the previous case, the second model with all the predictors is significantly better than the constant only model $\left(\chi^{2}=60.118, \mathrm{df}=10\right.$, and $\left.p<.001\right)$ and fits the analyzed data $\left(\chi^{2}=7.350, d f=8\right.$, and $\left.p>.05\right)$.

As for students, the same set of variables was implemented, excluding the question regarding the reasons for which respondents started to participate in distance learning practices (the question was not included in the questionnaire). Instead of this, their personal attitude to distance learning before the COVID-19 pandemic was taken into account. Also, this model with all the predictors is significantly better than the constant only model $\left(\chi^{2}=311.261, d f=6\right.$, and $\left.p<.001\right)$ and fits the analyzed data $\left(\chi^{2}=2.054, d f=5\right.$, and $\left.p>.05\right)$. The distributions of all predictors that were used in the three models are described in Table 2.

Table 2: Distribution of characteristics potentially determining the willingness to use distance learning after the COVID-19 pandemic

\begin{tabular}{|c|c|c|c|c|c|}
\hline & & \multicolumn{4}{|c|}{ Category of respondent } \\
\hline & & \multicolumn{2}{|c|}{ Teacher } & \multicolumn{2}{|c|}{ Student } \\
\hline & & $\mathrm{N}$ & $\%$ of $\mathrm{N}$ & $\mathrm{N}$ & $\%$ of $\mathrm{N}$ \\
\hline \multirow{2}{*}{$\begin{array}{l}\text { Department ( } 41 \text { teachers and } 128 \\
\text { students did not specify to which } \\
\text { department they belong ) }\end{array}$} & Humanities & 175 & $73.8 \%$ & 1589 & $73.1 \%$ \\
\hline & Science & 62 & $26.2 \%$ & 584 & $26.9 \%$ \\
\hline \multirow{2}{*}{$\begin{array}{l}\text { Sex( } 40 \text { teachers and } 194 \text { students did } \\
\text { not specify their sex) }\end{array}$} & Female & 141 & $59.2 \%$ & 1603 & $76.1 \%$ \\
\hline & Male & 97 & $40.8 \%$ & 504 & $23.9 \%$ \\
\hline \multirow{4}{*}{$\begin{array}{l}\text { Experience in using distance learning } \\
\text { methods }\end{array}$} & $\begin{array}{l}\text { Since the beginning of the } \\
\text { COVID-19 pandemic }\end{array}$ & 226 & $81.9 \%$ & 2181 & $94.9 \%$ \\
\hline & Less than 1 year & 13 & $4.7 \%$ & 65 & $2.8 \%$ \\
\hline & $1-2$ years & 16 & $5.8 \%$ & 32 & $1.4 \%$ \\
\hline & At least 3 years & 21 & $7.6 \%$ & 19 & $0.8 \%$ \\
\hline \multirow{2}{*}{$\begin{array}{l}\text { Positive attitude before the COVID-19 } \\
\text { pandemic }\end{array}$} & No & - & - & 1544 & $67.1 \%$ \\
\hline & Yes & - & - & 757 & $32.9 \%$ \\
\hline \multicolumn{6}{|c|}{ Reasons for which the teachers started to participate in distance learning practices } \\
\hline \multirow{2}{*}{ Time efficiency } & No & 224 & $80.6 \%$ & - & - \\
\hline & Yes & 54 & $19.4 \%$ & - & - \\
\hline \multirow{2}{*}{ Rector's decision } & No & 207 & $74.5 \%$ & - & - \\
\hline & Yes & 71 & $25.5 \%$ & - & - \\
\hline \multirow{2}{*}{$\begin{array}{l}\text { Desire to continue teaching during the } \\
\text { COVID-19 pandemic }\end{array}$} & No & 78 & $28.1 \%$ & - & - \\
\hline & Yes & 200 & $71.9 \%$ & - & - \\
\hline \multirow{2}{*}{ Better effectiveness } & No & 205 & $73.7 \%$ & - & - \\
\hline & Yes & 73 & $26.3 \%$ & - & - \\
\hline \multirow{2}{*}{$\begin{array}{l}\text { Willingness to use another form of } \\
\text { teaching }\end{array}$} & No & 206 & $74.1 \%$ & - & - \\
\hline & Yes & 72 & $25.9 \%$ & - & - \\
\hline
\end{tabular}


Among teachers, the need to conduct distance learning courses during the national lockdown does not have a positive impact on the willingness to continue this practice in the future, i.e. after overcoming the COVID-19 crisis. It is well confirmed by logistic regression models directed towards identification of factors which explain the teachers' willingness to use distance learning methods after obligatory emergency remote teaching during the COVID-19 pandemic.

The first model ( $\mathrm{N}=231$; the model does not take into account teachers who did not specify their sex or department; Table 3) shows that predictors increasing willingness of teachers to continue classes and lectures after the COVID-19 pandemic with distance learning methods are connected with the desire to achieve better effectiveness of teaching and testing a new teaching method (accordingly, Exp $(B)=2.524 ; p<.01$ and Exp $(B)=2.649 ; p<.01)$. Contrary to this, factors directly related to the pandemic situation significantly reduce the probability of willingness to conduct classes and lectures in this form in the future $(\operatorname{Exp}(B)=0.374 ; p<.01$ in the case of desire to continue teaching during the COVID-19 pandemic) or do not have a statistically significant effect (as in the case of the Rector's decision).

Similar results are provided by the second model ( $\mathrm{N}=231$; the model does not take into account teachers who did not specify their sex or department; Table 3), which includes an additional variable regarding the previous (i.e. gained before the COVID-19 pandemic) teachers' experience with distance learning. This extra variable not only improves parameters of the model (the change of size of Nagelkerke R from 0.221 to 0.310 indicates that Model II better predicts attitude to distance learning in the future) but also shows that a few years' experience in distance learning significantly increases the willingness to use distance learning methods in the future (Exp $(B)=22.202 ; p<.01$ among teachers with $1-2$ years experience and $\operatorname{Exp}(B)=5.293 ; p<.05$ among teachers with at least 3 years' experience).

Table 3: Predictors of willingness to use distance learning after the COVID-19 pandemic among teachers

\begin{tabular}{|c|c|c|c|c|}
\hline & \multicolumn{2}{|c|}{ Model I } & \multicolumn{2}{|c|}{ Model II } \\
\hline & Wald & $\operatorname{Exp}(B)$ & Wald & $\operatorname{Exp}(B)$ \\
\hline Type of department & 2.213 & 1.684 & 3.486 & 1.989 \\
\hline Sex & 0.935 & 0.742 & 1.390 & 0.681 \\
\hline Time efficiency & 0.870 & 1.415 & 0.003 & 1.024 \\
\hline Rector's decision & 0.125 & 0.880 & 0.361 & 1.255 \\
\hline $\begin{array}{l}\text { Desire to continue teaching during the COVID-19 } \\
\text { pandemic }\end{array}$ & 8.648 & $.374 * *$ & 3.020 & 0.528 \\
\hline Better effectiveness & 7.292 & $2.524 * *$ & 7.418 & $2.659 * *$ \\
\hline Willingness to use another form of teaching & 8.167 & $2.649 * *$ & 8.888 & $2.923 * *$ \\
\hline $\begin{array}{l}\text { Experience: since the beginning of the COVID-19 } \\
\text { pandemic }\end{array}$ & - & - & 13.331 & \\
\hline Experience: less than 1 year & - & - & 0.582 & 1.664 \\
\hline Experience: $1-2$ years & - & - & 7.897 & $22.202 * *$ \\
\hline Experience: at least 3 years & - & - & 6.489 & $5.293^{*}$ \\
\hline Constant & 0.833 & 1.697 & 4.709 & $0.402 *$ \\
\hline Cox and Snell R2 & .164 & & .229 & \\
\hline Nagelkerke R2 & .221 & & .310 & \\
\hline-2 Log likelihood & 270.090 & & 251.293 & \\
\hline
\end{tabular}

$* \mathrm{p}<.05 ; * * \mathrm{p}<.01$

It is also important to note that the sex and type of department represented by the survey responders are not statistically significant predictors. Therefore there is no evidence that they affect the willingness to use distance learning methods after the COVID-19 pandemic.

A similar conclusion could be made in the case of students' answers. Their need to participate in distance learning courses during the national lockdown does not have a statistically significant impact on the willingness to take part in such activities in the future, which is confirmed by the model presented below (Nagelkerke $\mathrm{R}=$ 0.189; $N=2102$; the model does not take into account students who did not specify their sex or department) (Table 4). Contrary to this, a positive attitude to distance learning before the COVID-19 pandemic increases willingness to take part in distance learning courses in the future $(\operatorname{Exp}(B)=5.260 ; p<.001)$. A statistically significant difference could also be observed in the case of type of department represented by students: 
respondents who are studying science are more willing to participate in distance learning when compared to those studying humanities $(\operatorname{Exp}(B)=1.487 ; p<.001)$.

Table 4: Predictors of willingness to use distance learning after COVID-19 among students

\begin{tabular}{|c|c|c|}
\hline & Wald & $\operatorname{Exp}(B)$ \\
\hline Type of department & 12.845 & $1.487 * * *$ \\
\hline Sex & 0.489 & 1.085 \\
\hline Positive attitude before the COVID-19 pandemic & 261.433 & $5.260 * * *$ \\
\hline Experience: since the beginning of the COVID-19 pandemic & 2.689 & \\
\hline Experience: less than 1 year & 0.005 & 1.021 \\
\hline Experience: $1-2$ years & 1.674 & 1.757 \\
\hline Experience: at least 3 years & 1.053 & 1.728 \\
\hline Constant & 322.925 & $0.257 * * *$ \\
\hline Cox and Snell R2 & .138 & \\
\hline Nagelkerke R2 & .189 & \\
\hline-2 Log likelihood & 2417.107 & \\
\hline
\end{tabular}

In the light of the presented results, the first hypothesis - that the need to take part in distance learning activities during the national lockdown will not have a positive impact on willingness to use distance learning in the future - should be confirmed. The second hypothesis was supported by the results as well. All presented models show that the previous experience with distance learning, gained before the pandemic, strengthens the positive attitude of respondents to distance teaching in the future.

\subsection{Assessment of the advantages and disadvantages of distance learning among respondents with a positive and negative attitude to distance learning courses in the future}

The regression models described above show that the attitude of teachers and students is strongly influenced by personal experiences gained before the COVID-19 pandemic. However, does the analysis presented in the article allow us to conclude that willingness to conduct distance learning courses in the future is positively correlated with a better assessment of various distance learning aspects? To answer this question and verify the third hypothesis, a set of advantages and disadvantages of distance learning was defined based on feedback received from the participants of professional development courses taught by the Centre for Distance Learning since the year 2016. Regardless of our own experiences, very similar features of distance learning were taken into account in some international publications (Olson and Wisher 2002; Suanpang, Petocz, and Walter 2004; Derouin, Fritzsche, and Salas 2005; Vu et al. 2014; Al-Azawei, Parslow, and Lundqvist 2016). In order not to miss any important feature, respondents had an opportunity to define advantages and disadvantages on their own, but they did not provide any additional information on the relevant pros and cons of distance learning.

The distance learning advantages and disadvantages were assessed among teachers and students belonging to the following four categories mentioned in chapter 2: (1) teachers willing to use distance learning after the COVID-19 pandemic, (2) teachers not willing to use distance learning after the COVID-19 pandemic, (3) students willing to use distance learning after the COVID-19 pandemic and (4) students not willing to use distance learning after the COVID-19 pandemic. This step was necessary to better understand what kind of activities should be taken into account to encourage the academic community to not discontinue distance learning after the COVID-19 pandemic. A 6-item set of questions about the advantages and a 4-item set of questions about the disadvantages were applied. The assessment was made using a five-level Likert rating of multiple items (scale ranges from Definitely no $\{1\}$ No $\{2\}$ Do not know $\{3\}$ Yes $\{4\}$ to Definitely yes $\{5\}$ ). The basic distributions of the assessments are presented in Tables 5 and 6 . 
Table 5: Distribution of assessments of distance learning advantages among teachers and students

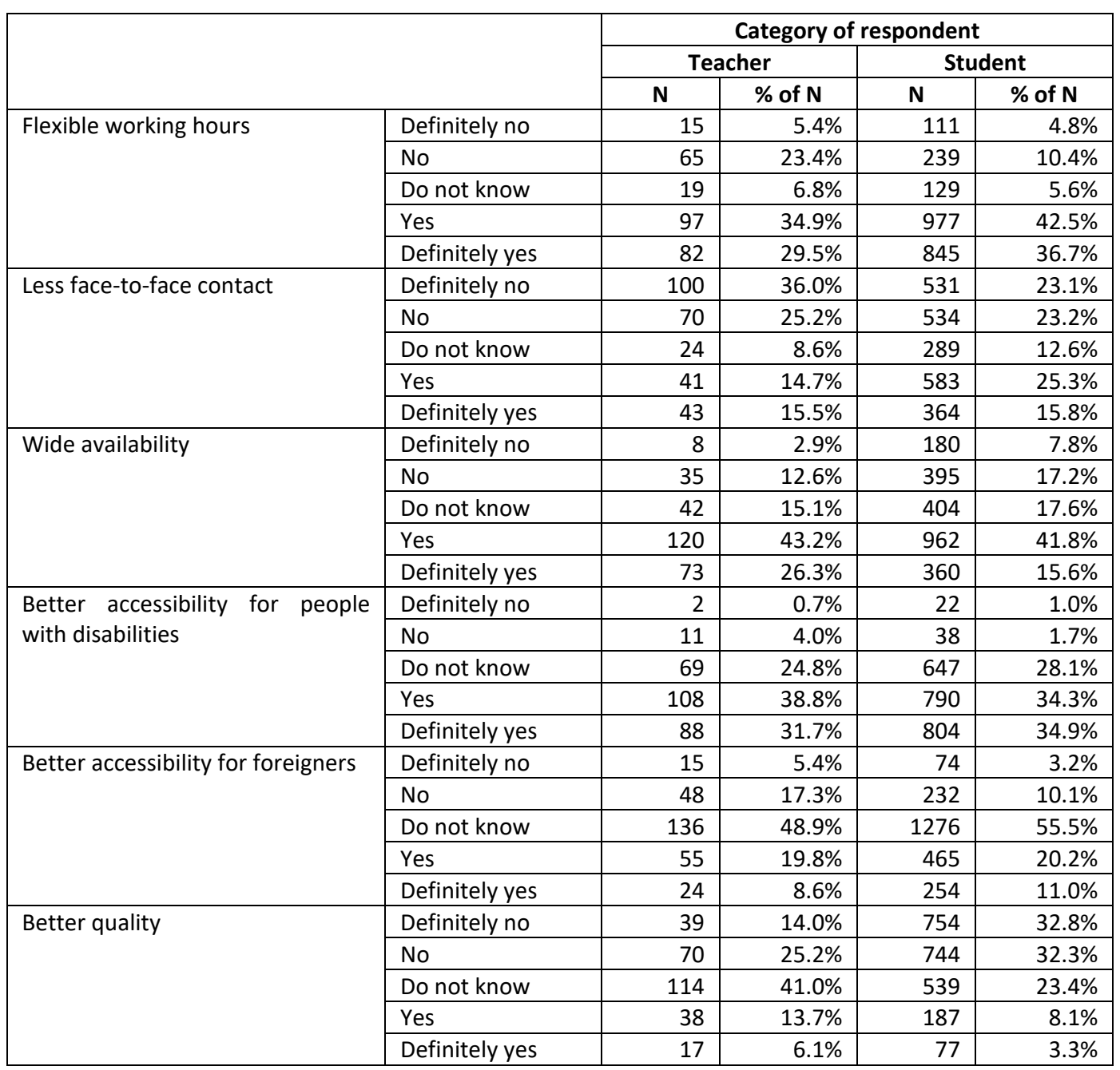

Table 6: Distribution of assessments of distance learning disadvantages among teachers and students

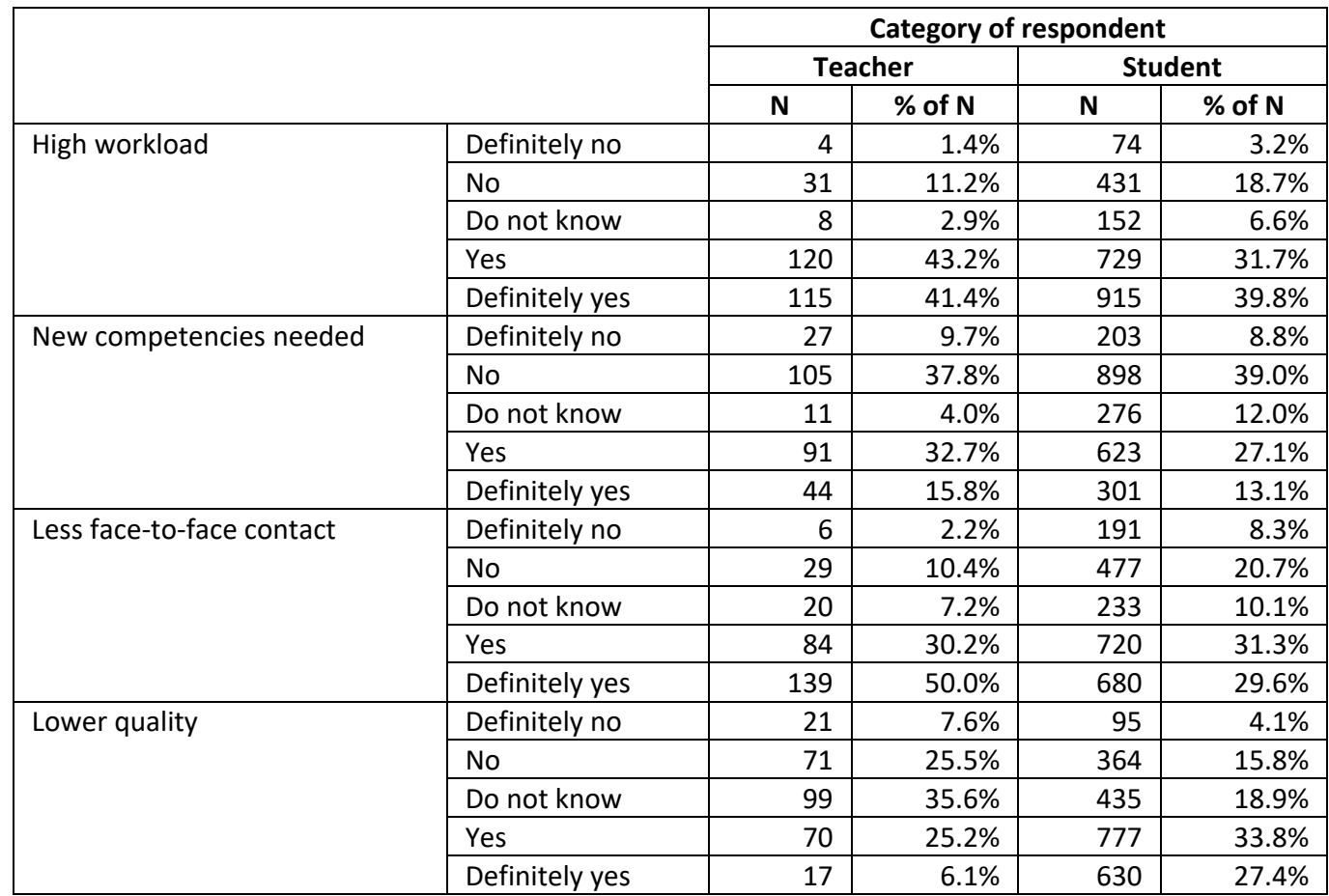


For more detailed analysis, the respondents' responses were converted into numerical values as follows: 0 points were given for "Definitely no", "No" and "Do not know". The "Yes" answer was assigned 1 point and the "Definitely yes" answer 2 points. The number of points scored by four different categories of respondents (teachers willing and not willing to use distance learning in the future and students willing and not willing to use distance learning in the future) and median values calculated for each category are shown in box plots presented in section 3.2 (Figures 2 and 3).

The number of points gained by teachers and students while evaluating advantages and disadvantages of distance learning suggests that the respondents' perception is correlated with the personal attitude to using distance learning in the future (Fig. 2). As the first box plot shows, the median value is greater in the case of respondents with a positive attitude to distance learning courses in the future.

It also follows that teachers and student groups with a similar attitude to distance learning courses in the future have nearly identical medians ( $\mathrm{Me}=3$ in the case of teachers and students who are not willing to use distance teaching in the future, and $\mathrm{Me}=4$ among teachers and students who are going to use distance teaching methods in the future). According to the logistic regression models presented in Tables 3 and 4, one should note that these positive assessments may be due to the adequate training and high competencies that were gained before the emergency distance learning organized under the COVID-19 pandemic pressure. Nevertheless, given the much longer whiskers for teachers and students interested in future participation in the distance learning initiatives, it should be emphasized that their assessments of advantages vary more widely than among respondents who do not want to continue distance learning practices.

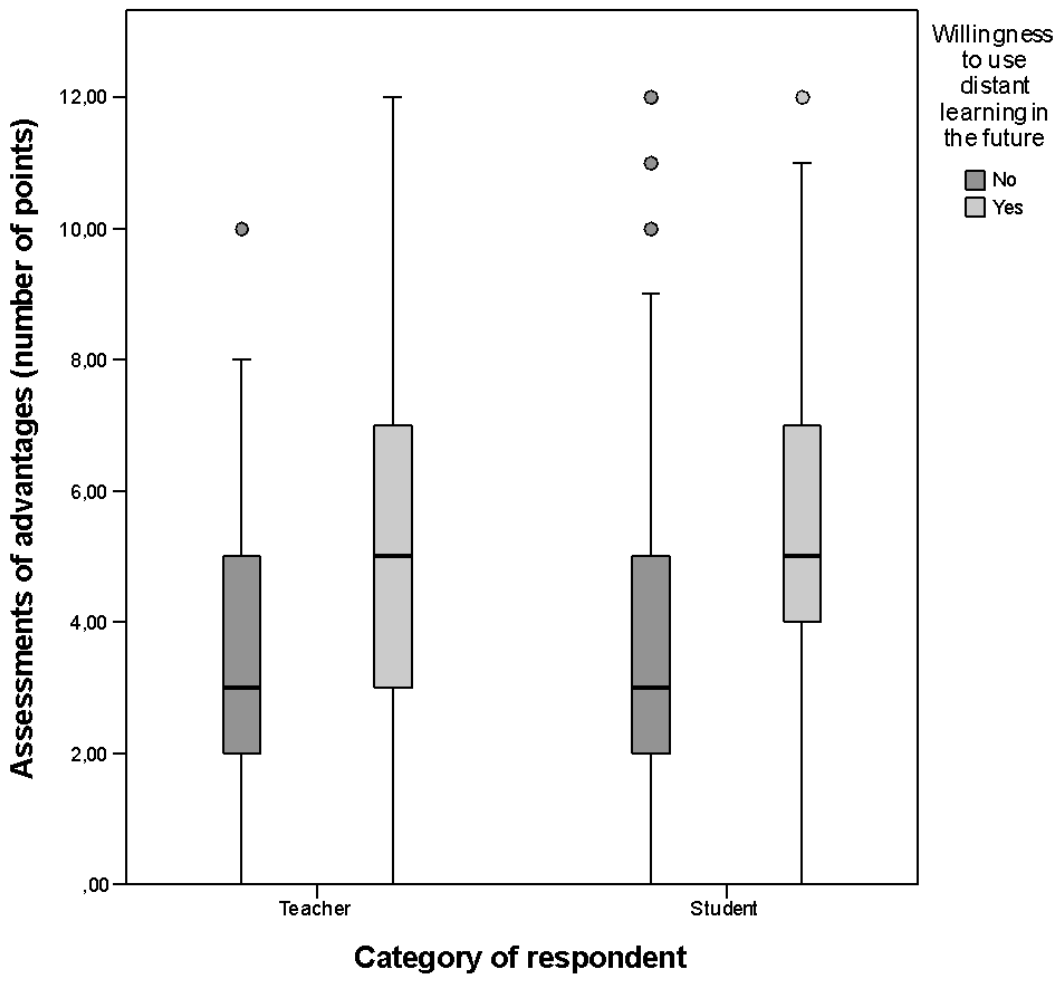

Figure 2: Assessment of advantages of distance learning among respondents (teachers - left part of the box plot, and students - right part of the box plot) with negative (dark) or positive (light) attitude to distance learning courses in the future

In turn, assessment of the disadvantages of distance learning suggests that nearly identical medians could be identified only in the case of teachers and students with a negative attitude to distance learning courses in the future (in both cases $\mathrm{Me}=4$ ). Contrary to this, medians calculated for teachers and students who are willing to use distance teaching in the future are different ( $\mathrm{Me}=3$ among teachers and $\mathrm{Me}=2$ among students), which suggests that the students' attitude towards distance learning is less critical (Fig. 3). Moreover, as in the case of analysis regarding advantages of distance learning, whiskers for teachers and students interested in future participation in the distance learning initiatives are longer. This result indicates that opinions about 
disadvantages expressed by the distance learning supporters vary more widely than among respondents who do not want to continue the distance learning practices.

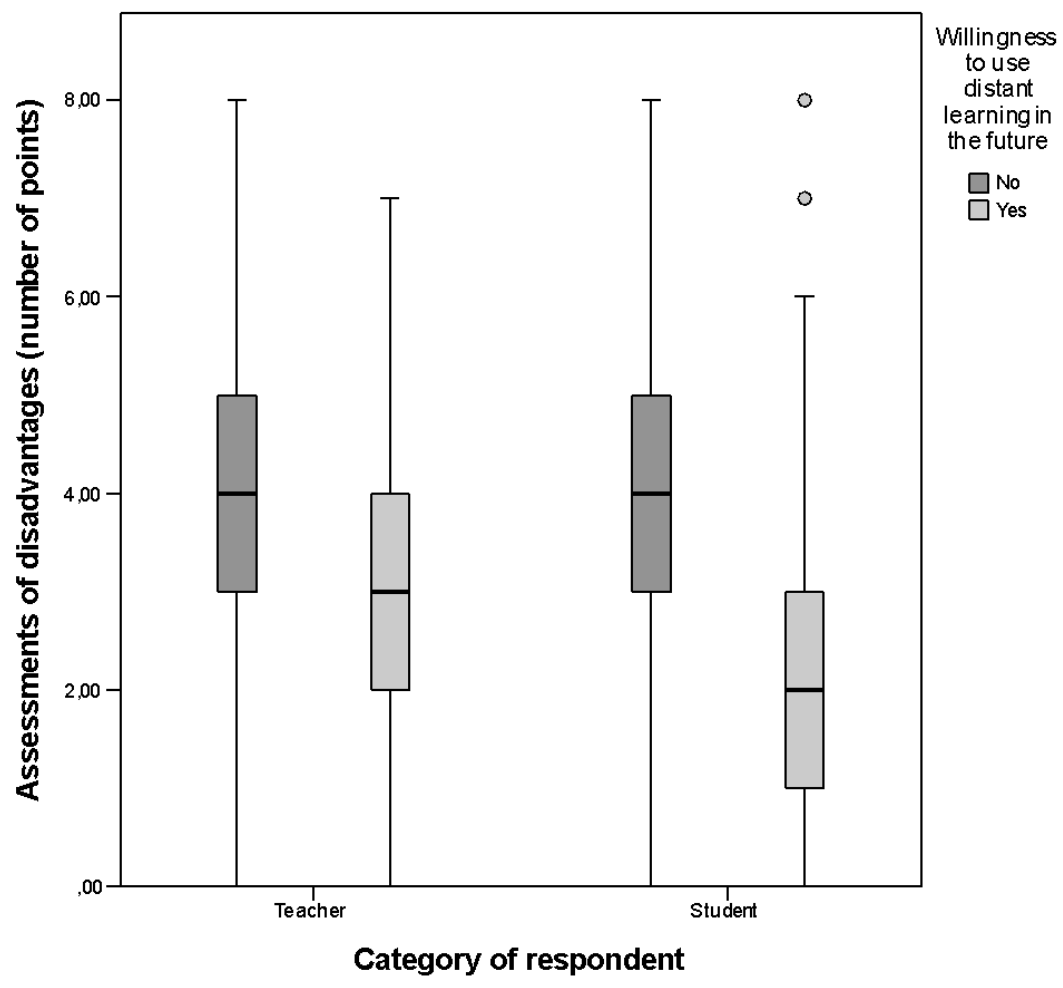

Figure 3: Assessment of disadvantages of distance learning among respondents (teachers - left part of the box plot, and students - right part of the box plot) with negative (dark) or positive (light) attitude to distance learning courses in the future

This statement is well confirmed by the results of the Mann-Whitney $U$ test comparing differences between scores obtained by teachers and students belonging to the four different categories (teachers willing and not willing to use distance learning in the future and students willing and not willing to use distance learning in the future). The results of the study show that the academic community members, both teachers and students, who are willing to participate in distance learning after lockdown achieve greater values of medium ranks in the first and third rows of Table 7, which means that they better assess the advantages of distance learning when compared to those who are not willing to be involved in distance learning activities in the future. In turn, a positive attitude to use distance learning in the future is connected with lower medium ranks in the second and fourth rows of Table 7, which indicates a less critical assessment of the disadvantages of distance learning.

Contrary to the previous statement, the professional status of respondents is not one of the factors for which a statistically significant difference was found between opinions of students and teachers belonging to the four different categories (similar medium ranks). The only exception is the assessment of disadvantages by teachers and students who want to participate in the distance learning courses in the future. In that case, the students' attitude towards distance learning is significantly less critical than among teachers (students' medium rank is lower than teachers' rank). 
Table 7: Results of Mann-Whitney $U$ test comparing differences between teachers and students in assessment of advantages and disadvantages of distance learning

Group 1: Teachers willing to use distance learning after the COVID-19 pandemic Group 2: Teachers not willing to use distance learning after the COVID-19 pandemic Group 3: Students willing to use distance learning after the COVID-19 pandemic Group 4: Students not willing to use distance learning after the COVID-19 pandemic

\begin{tabular}{|c|c|c|c|c|c|c|}
\hline Comparing groups & $\mathbf{N}$ & $\mathbf{U}$ value & $\boldsymbol{Z}$ & Significance & $\begin{array}{c}\text { Medium rank } \\
\text { for first group }\end{array}$ & $\begin{array}{c}\text { Medium rank } \\
\text { for right group }\end{array}$ \\
\hline $\begin{array}{c}\text { Assessment of advantages: } \\
\text { 1 vs. 2 }\end{array}$ & 278 & 5710.5 & -5.286 & .000 & 171.59 & 120.32 \\
\hline $\begin{array}{c}\text { Assessment of disadvantages: } \\
\text { 1 vs. } 2\end{array}$ & 278 & 6385.0 & -4.311 & .000 & 113.89 & 154.80 \\
\hline $\begin{array}{c}\text { Assessment of advantages: } \\
\text { 3 vs. } 4\end{array}$ & 2301 & 369674.5 & $\begin{array}{c}15.87 \\
4\end{array}$ & .000 & 1440.52 & 991.61 \\
\hline $\begin{array}{c}\text { Assessment of disadvantages: } \\
\text { 3 vs. } 4\end{array}$ & 2301 & 344209.0 & $\begin{array}{c}17.75 \\
3\end{array}$ & .000 & 830.31 & 1327.55 \\
\hline $\begin{array}{c}\text { Assessment of advantages: } \\
\text { 2 vs.4 }\end{array}$ & 1658 & 123543.0 & -.953 & .338 & 861.48 & 825.75 \\
\hline $\begin{array}{c}\text { Assessment of disadvantages: } \\
\text { 2 vs.4 }\end{array}$ & 1658 & 128038.5 & -.187 & .851 & 823.35 & 830.22 \\
\hline $\begin{array}{c}\text { Assessment of advantages: } \\
\text { 1 vs.3 }\end{array}$ & 921 & 42370.0 & -.046 & .963 & 459.90 & 461.14 \\
\hline $\begin{array}{c}\text { Assessment of disadvantages: } \\
\text { 1 vs.3 }\end{array}$ & 921 & 47830.0 & -3.158 & .002 & 535.87 & 451.47 \\
\hline
\end{tabular}

To conduct a deep analysis of the perception of distance learning advantages and disadvantages, additional graphs with a particular feature rating (Fig. 4 and 5) were prepared. All members of the academic community agree that among the substantial distance learning advantages the flexible working hours are one of the most important. $64.4 \%$ of teachers and $79.2 \%$ of students indicated flexibility as an important or very important distance learning benefit (answers "yes" and "definitely yes"). Most of responders also admit that distance learning offers better accessibility for people with disabilities (this opinion was expressed by $70.5 \%$ of teachers and $69.2 \%$ of students participating in the survey). Another important advantage indicated by all categories of respondents is a wide availability of this form of education (69.5\% of teachers and $57.4 \%$ of students) (Fig.4).

a) Teachers

Better quality
Better accesibility for foreigners

Better accesibility for people with disabilities

Wide availability

Less face-to-face contacts

Flexible working hours

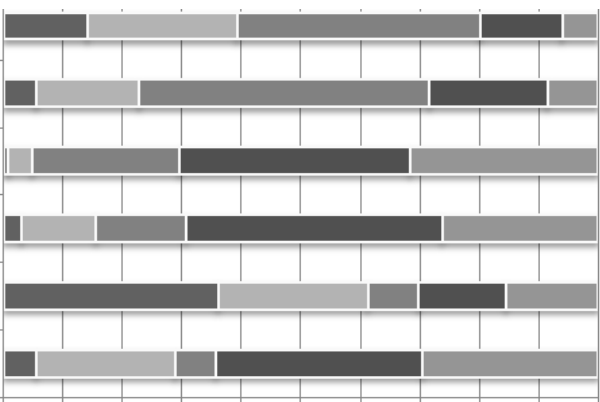

ஃ

- Definitely no $\because$ No $\square$ Do not know $\because$ Yes $\square$ Definitelyyes

b) Students 


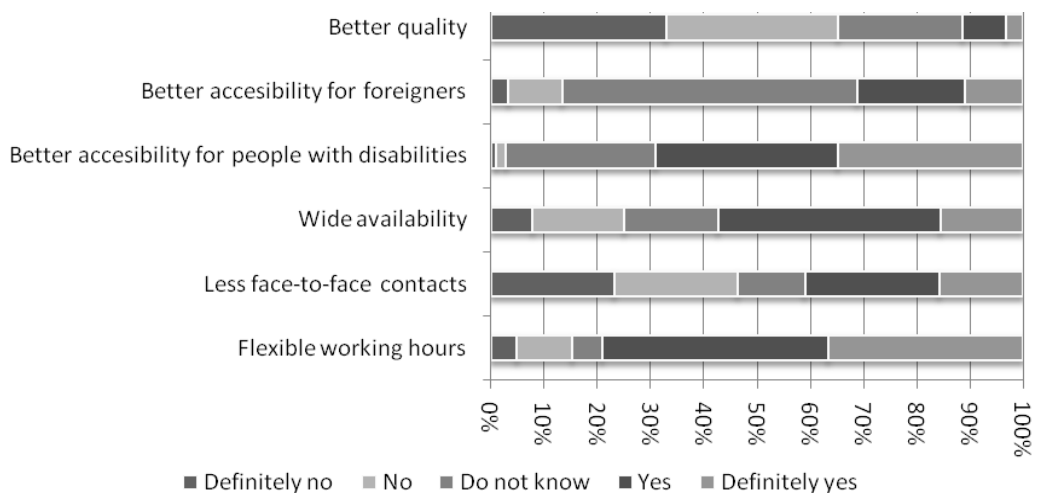

Figure 4: Assessment of distant learning advantages among teachers (upper figure) and students (lower figure)

Among the main disadvantages of distance education, both groups of respondents indicated a high workload. $84.6 \%$ of teachers and $71.5 \%$ of students indicated this issue. Taking into consideration the emergency, those responses could be influenced by specific, very stressful, and unusual circumstances. The lack of social, face-toface interactions was assessed as a disadvantage by $80.2 \%$ of teachers and $60.9 \%$ of students (Fig. 5). Since the whole academic community, both teachers and students, also indicated that an important disadvantage of distance learning is a lack of appropriate competencies, blended learning might be a valuable and reasonable solution that provides balance in the learning routine based on traditional and distance learning techniques. Although students do not miss the face-to-face contact, they more often indicate that the distance learning methods are characterized by lower quality than traditional forms of education. According to the respondents' opinions, $61.2 \%$ of students are not satisfied with the quality of the distance teaching classes, while among teachers the dissatisfaction rate was estimated at $31.3 \%$. It means that the way in which teachers use the distance teaching methods probably does not provide enough opportunities to effectively transfer knowledge and create new skills among students.

a) Teachers

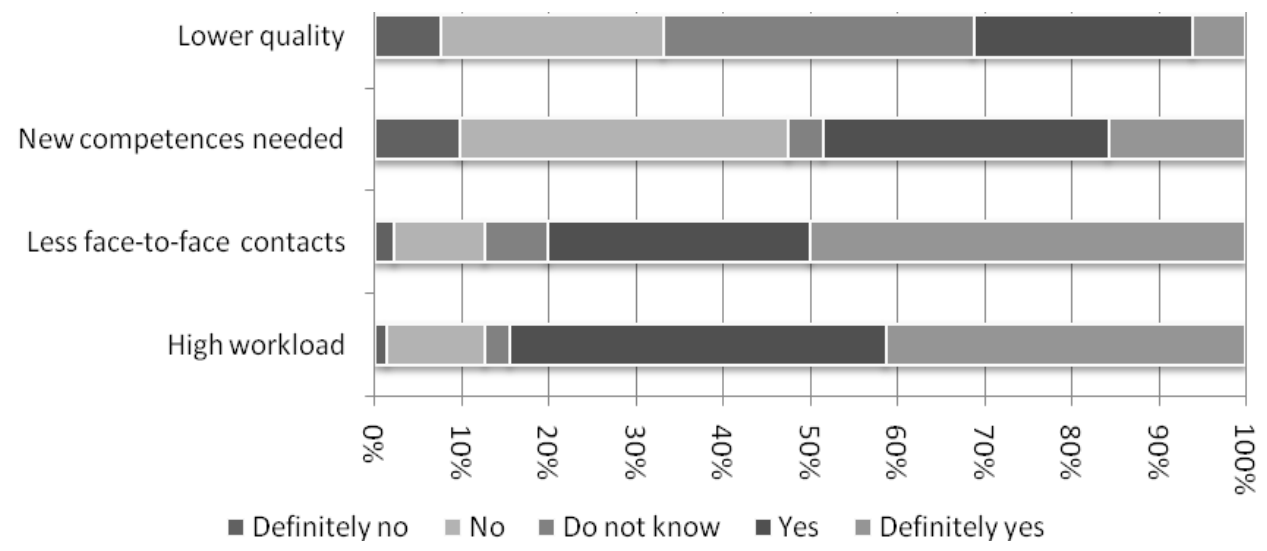


b) Students

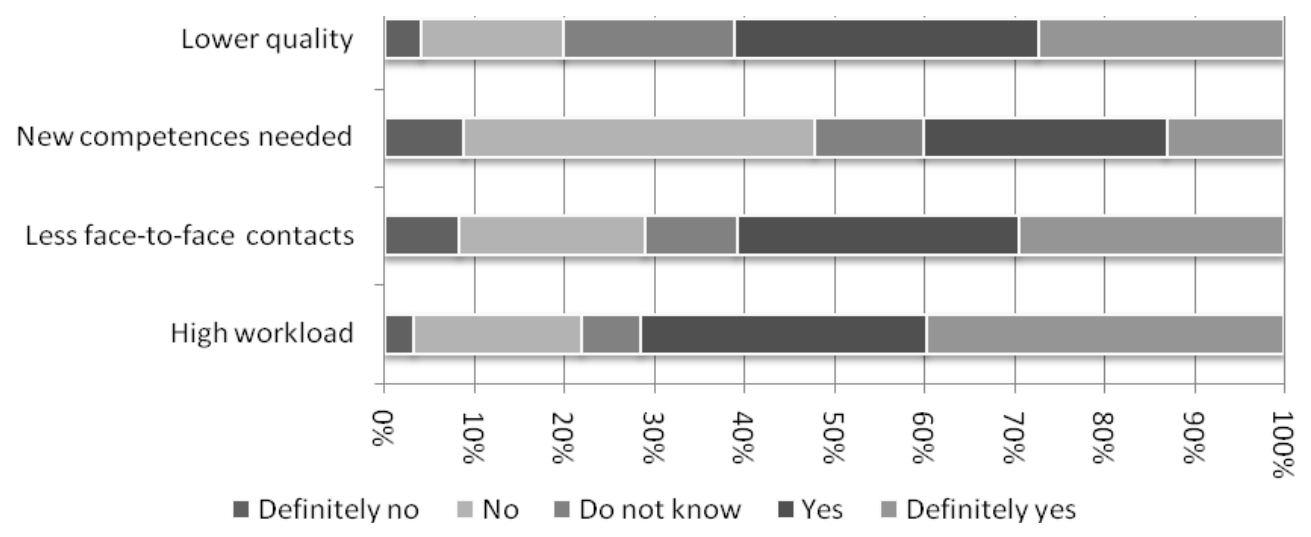

Figure 5: Assessment of distant learning disadvantages among teachers (upper figure) and students (lower figure)

To provide a detailed picture of assessments of advantages and disadvantages, an additional comparison between respondents willing to continue distance learning and not interested in distance teaching was developed. Results of the chi-square tests of independence presented in Tables 8 and 9 provide three general conclusions. Firstly, teachers and students who would like to continue this form of education in the future, more often indicate advantages of distance learning than teachers and students who are not interested in this form of education. Adherents of distance learning express a more positive attitude to all benefits that were investigated (Table 8).

Table 8: A detailed assessment of advantages of distance learning among teachers and students (in \%; "do not know" answers are excluded)

Group 1: Teachers willing to use distance learning after COVID-19 pandemic Group 2: Teachers not willing to use distance learning after COVID-19 pandemic Group 3: Students willing to use distance learning after COVID-19 pandemic Group 4: Students not willing to use distance learning after COVID-19 pandemic

\begin{tabular}{|c|c|c|c|c|c|}
\hline & \multicolumn{3}{|c|}{$\begin{array}{l}\text { Not agree that this is an } \\
\text { advantage of distance } \\
\text { learning* }\end{array}$} & \multirow{2}{*}{$\begin{array}{l}\text { Agree that this is } \\
\text { an advantage of } \\
\text { distance learning** } \\
\text { 足 } \\
\text { 定 }\end{array}$} & \\
\hline & $\begin{array}{l}0 \\
\frac{0}{0} \\
\frac{0}{0} \\
\mapsto\end{array}$ & 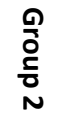 & $\begin{array}{l}\stackrel{0}{0} \\
\stackrel{0}{0} \\
\text { ㅁ }\end{array}$ & & \\
\hline Flexible working hours & 18.3 & 35.1 & 75.0 & 58.0 & $\begin{array}{c}\chi^{2}=23.860, d f=4 \\
p<.001, V=.29\end{array}$ \\
\hline Less face-to-face contact & 53.8 & 65.5 & 32.7 & 28.7 & $\begin{array}{c}\chi^{2}=10.244, d f=4 \\
p<.05, V=.19\end{array}$ \\
\hline Wide availability & 8.7 & 19.5 & 81.7 & 62.1 & $\begin{array}{c}\chi^{2}=17.798, d f=4 \\
p<.01, V=.23\end{array}$ \\
\hline $\begin{array}{c}\text { Better accessibility for people with } \\
\text { disabilities }\end{array}$ & 1.0 & 6.9 & 79.8 & 64.9 & $\begin{array}{c}\chi^{2}=13.089, d f=4 \\
p<.05, V=.21\end{array}$ \\
\hline Better accessibility for foreigners & 17.3 & 25.9 & 37.5 & 23.0 & $\begin{array}{c}\chi^{2}=7.928, d f=4, p>.05, \\
V=.17\end{array}$ \\
\hline Better quality & 20.5 & 50.6 & 37.5 & 9.2 & $\begin{array}{c}\chi^{2}=47.262, d f=4 \\
p<.001, V=.41\end{array}$ \\
\hline
\end{tabular}




\begin{tabular}{|c|c|c|c|c|c|}
\hline & \multicolumn{3}{|c|}{$\begin{array}{c}\text { Not agree that this is an } \\
\text { advantage of distance } \\
\text { learning* }\end{array}$} & \multirow[t]{2}{*}{$\begin{array}{l}\text { Agree that this is } \\
\text { an advantage of } \\
\text { distance learning** }\end{array}$} & \\
\hline & $\begin{array}{l}0 \\
0 \\
\frac{0}{0} \\
\text { w }\end{array}$ & $\begin{array}{l}0 \\
0 \\
\frac{1}{0} \\
0 \\
D\end{array}$ & $\begin{array}{l}0 \\
0 \\
\frac{1}{0} \\
\text { w }\end{array}$ & & \\
\hline Flexible working hours & 5.9 & 20.4 & 91.8 & 72.2 & $\begin{array}{c}\chi^{2}=305.274, d f=4, \\
p<.001, V=.36\end{array}$ \\
\hline Less face-to-face contact & 32.8 & 53.7 & 50.3 & 36.1 & $\begin{array}{c}\chi^{2}=118.494, d f=4, \\
p<.001, V=.23\end{array}$ \\
\hline Wide availability & 9.3 & 33.6 & 78.9 & 45.6 & $\begin{array}{c}\chi^{2}=341.601, d f=4, \\
p<.001, V=.37\end{array}$ \\
\hline $\begin{array}{c}\text { Better accessibility for people with } \\
\text { disabilities }\end{array}$ & 1.5 & 3.2 & 77.6 & 64.7 & $\begin{array}{c}\chi^{2}=91.820, d f=4, \\
p<.001, V=.20\end{array}$ \\
\hline Better accessibility for foreigners & 8.1 & 16.2 & 38.6 & 27.2 & $\begin{array}{c}\chi^{2}=97.646, d f=4, \\
p<.001, V=.20\end{array}$ \\
\hline Better quality & 37.1 & 80.5 & 25.7 & 3.6 & $\begin{array}{c}\chi^{2}=535.617, d f=4, \\
p<.001, V=.48\end{array}$ \\
\hline
\end{tabular}

* recoded answers "no" and "definitely no"

** recoded answers "yes" and "definitely yes"

Secondly, similar conclusion could be made in the case of assessment of the distance learning disadvantages, but the results achieved here seem to be a mirror image of the previous evaluation (Table 9). Those who do not want to continue this form of teaching in the future, more often indicate disadvantages than teachers and students who are interested in the distance learning. Moreover, this more negative attitude concerns all detailed cons that were investigated in the following study.

In this context, it is worth noting that both conclusions allow us to confirm the third hypothesis assuming that the positive attitude to distance learning in the future is connected not only with a more positive assessment of advantages of distance learning but also with a less critical attitude to its weaknesses.

Table 9: A detailed assessment of disadvantages of distance learning among teachers and students (in \%; answers "do not know" are excluded)

Group 1: Teachers willing to use distance learning after the COVID-19 pandemic Group 2: Teachers not willing to use distance learning after the COVID-19 pandemic Group 3: Students willing to use distance learning after the COVID-19 pandemic Group 4: Students not willing to use distance learning after the COVID-19 pandemic

\begin{tabular}{|c|c|c|c|c|c|}
\hline & \multicolumn{2}{|c|}{$\begin{array}{l}\text { Not agree that } \\
\text { this is a } \\
\text { disadvantage of } \\
\text { distance } \\
\text { learning* }\end{array}$} & \multicolumn{2}{|c|}{$\begin{array}{l}\text { Agree that this } \\
\text { is a } \\
\text { disadvantage of } \\
\text { distance } \\
\text { learning** }\end{array}$} & \\
\hline & 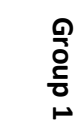 & $\begin{array}{l}\text { Q } \\
\text { o } \\
\text { c } \\
\text { N }\end{array}$ & $\begin{array}{l}\stackrel{9}{0} \\
\stackrel{0}{0} \\
\stackrel{5}{\circ}\end{array}$ & 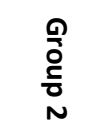 & \\
\hline High workload & 16.3 & 10.3 & 82.7 & 85.6 & $\chi^{2}=8.089, d f=4, p>.05, V=.17$ \\
\hline Less face-to-face contacts & 54.8 & 43.1 & 41.3 & 52.9 & $\chi^{2}=14.546, d f=4, p<.01, V=.23$ \\
\hline New competences needed & 13.5 & 12.1 & 74.0 & 83.9 & $\chi^{2}=14.130, d f=4, p<.01, V=.22$ \\
\hline Lower quality & 51.9 & 21.8 & 13.5 & 42.0 & $\chi^{2}=37.559, \mathrm{df}=4, p<.001, V=.37$ \\
\hline
\end{tabular}




\begin{tabular}{|c|c|c|c|c|c|}
\hline & \multicolumn{2}{|c|}{$\begin{array}{l}\text { Not agree that } \\
\text { this is a } \\
\text { disadvantage of } \\
\text { distance } \\
\text { learning * }\end{array}$} & \multicolumn{2}{|c|}{$\begin{array}{l}\text { Agree that this } \\
\text { is a } \\
\text { disadvantage of } \\
\text { distance } \\
\text { learning** }\end{array}$} & \\
\hline & $\begin{array}{l}\stackrel{Q}{0} \\
\stackrel{0}{0} \\
\frac{1}{0} \\
\omega\end{array}$ & $\begin{array}{l}\text { Q } \\
\text { Oे } \\
\frac{1}{0} \\
\stackrel{D}{0}\end{array}$ & $\begin{array}{l}0 \\
\frac{0}{0} \\
\frac{1}{0} \\
\omega\end{array}$ & 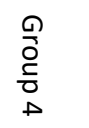 & \\
\hline High workload & 30.1 & 17.5 & 62.4 & 76.4 & $\chi^{2}=64.828, d f=4, p<.001, V=.17$ \\
\hline Less face-to-face contacts & 60.1 & 41.1 & 48.0 & 67.9 & $\chi^{2}=143.986, d f=4, p<.001, V=.25$ \\
\hline New competences needed & 41.2 & 22.3 & 30.8 & 45.3 & $\chi^{2}=89.555, d f=4, p<.001, V=.20$ \\
\hline Lower quality & 39.0 & 9.4 & 35.7 & 75.1 & $\chi^{2}=435.257, d f=4, p<.001, V=.43$ \\
\hline
\end{tabular}

* recoded answers "no" and "definitely no"

** recoded answers "yes" and "definitely yes"

Thirdly, although teachers and students who are adherents of distance learning differ in terms of the exact percentages, the general shape of their opinions is similar. As compared to teachers and students who are not willing to use distance learning in the future, they more frequently indicate all advantages and less frequently indicate the evaluated cons. This conclusion is consistent with results of the already discussed Mann-Whitney $U$ tests and supports the previously presented statement that even if the professional status sometimes influences the respondents' opinion, usually this is not an important reason for differences between adherents and opponents of distance learning.

\section{Discussion}

It can be concluded that indeed the experience in the distance learning gained before the COVID-19 pandemic outbreak positively influences the academic community's attitude towards distance learning. However, it was also found that the emergency distance teaching does not have a positive impact on the attitude to use distance learning methods in the future.

In addition, it was found that the perception of advantages and disadvantages of distance learning varies according to the willingness to use distance learning in the future: respondents with a positive attitude to distance teaching more often indicate its advantages, such as flexible working hours, flexibility, better accessibility and wide availability of this form of education. They also less frequently pay attention to its disadvantages, which include high workload and lower quality of classes. In contrast, assessment of the advantages and disadvantages is convergent for respondents with the same attitude to distance learning, regardless of their professional status (being a teacher or student).

The attitude to distance learning methods and satisfaction with their use among academic staff are of great importance for motivation and students' outcomes. The former directly affects the latter (Viegas et al. 2018). Hence, the proper training of academic staff is highly important for the effectiveness of education that takes place through distance learning. This corresponds with our results. The more experienced and acquainted with distance learning techniques the teachers are, the more willingly they declare interest in the continuing education of students using distance learning techniques after the national lockdown.

Implementing large-scale distance learning in crisis conditions such as a national lockdown is a challenge and can potentially be a source of frustration and overload. To improve the attitude to distance learning among participants, limitations such as lack of skills need to be overcome. Of great importance are, particularly in the long term, training and workshops for the development of distance learning-associated skills with consideration of various levels of participants' competencies. Another key issue is to find the right amount of time to gain or develop competences and use them during the implementation of courses containing distance learning elements (Marasi, Jones, and Parker 2020). It can be assumed that this approach might encourage academic staff to tackle a challenge presented by a situation like the one encountered during the national 
lockdown. This will also translate into the further development of distance learning activities under normal conditions.

We are aware that our findings may be limited since the research was conducted just in one university. However, some other analyses are convergent with our conclusions, i.e. the comparison conducted in the USA, Mexico, Peru, and Turkey, shows that previous experience of the use of distance learning technology facilitates learning efficiency (Aguilera-Hermida et al. 2021). The same was true even for analysis performed in one academy, such as for nursing students in Turkey, where authors underline the fact that the gained experience is a factor, which improves the positive attitude (Terzi, Azizoğlu, and Özhan 2021). Taking in mind that our research outcomes may not be general, we believe that research on this level would provide valuable data in worldwide discussion regarding distance learning.

The traditional teaching techniques involving personal contact and face-to-face communication are irreplaceable, especially because of the vital role of non-verbal communication in the education process (Beebe 1980), but distance learning widens our set of learning tools and brings more powerful instruments. Also, in the opinion of the respondents, the effect of an emergency transition to distance learning during the national lockdown will be a reshaping of the education system at the University of Wrocław. Such a prognosis fits into the global trend (Krishnamurthy 2020; Whalen 2020). As one of the students' comments, regarding the future education, pointed out, "[the future] depends on how the university overcomes the situation. If it draws the right conclusions and incorporates some good solutions [...] and eliminates the unfavorable, there will be an improvement. Especially as the faculty was forced to acquire certain skills that will be beneficial in the future. [...]". These kinds of opinions were also true for teachers; as one of them wrote, "I think that the current situation will cause the development of new teaching procedures, which could be introduced in the case of such a crisis. Greater emphasis will be placed on distance learning, and employees will be obliged to undergo the appropriate training".

\section{Conclusions and Implications}

Based on the above-discussed results, some recommendations for more effective development of distance learning at large-scale institutions can be made. The most important factor that visibly changes the attitude towards distance learning is the training, experience, and knowledge regarding such a method of education. Those teachers who were fully trained in the distance learning design (based on the backward design methodology) are up to 22 times more eager to continue this kind of education after the pandemic (see table 3). A similar rule applies also to students who recognized the nature of distance learning before the COVID-19 pandemic. Their attitude towards distance learning is much more positive than their colleagues' who were taught by emergency remote teachers, which clearly shows the crucial role of teacher training in the student's success and satisfaction (see table 4). Previous experiences with distance learning were also a good opportunity to assess the effectiveness of this method. The study shows that teachers who positively assessed the effectiveness of distance learning before the pandemic were up to 2.7 times more eager to conduct similar courses in the future (see table 3).

What seems quite surprising is that the awareness of distance learning features and methods is a much more important factor than the COVID-19 crisis itself. Teachers who were forced to teach remotely because of the national lockdown have not changed their opinions about distance learning, in most cases listing more negative aspects of this type of education than their fellow teachers who did so of their own volition. This reaction plainly shows that no form of negative extrinsic motivation, even if reasonable, can be effective in the management of the transition from brick-and-mortar to online education. The only way is to create an environment where a positive attitude towards distance learning is gained step by step using "soft power" management.

One of the possibilities of transforming the institutional policy regarding distance education is to change the way the end-of-semester reports are made. This should include both teachers' and students' perspectives. Firstly, the end-of-semester reports should take into account the way of calculation of working hours, considering the differences between students which result from their abilities to achieve the learning outcomes. And secondly, what is important from the teachers' perspective, consider the differences between the working hours required to prepare a distance learning course compared to a conventional course. For this purpose, it would be useful to formulate appropriate guidelines for teachers, in the form of the so-called 
Catalogue of Best Practice, concerning, among other things, how to use distance learning tools. The catalog could be developed based on a focus group interview carried out with experienced distance learning participants (Gill, Stewart, and Treasure 2008). The mentioned issues are directly connected with one of the most often chosen virtues of distance learning - self-paced learning. Disregarding the often mentioned increased workload, both teachers and students praise this form of education, as it gives them the opportunity to work in a chosen place and time frame. Self-paced learning helps students work at their own rhythm, gaining planned learning outcomes at a different time. Therefore, the reported workload of remote teachers should be tied to learning outcomes instead of anticipated working hours. This would be a way of appreciation of the course effectiveness, encouraging more teachers to thoroughly reshape their courses, thus improving the overall quality of education in the whole institution.

Increased workload, which was often mentioned by teachers and students in their responses, is also in many cases the result of the under-preparation of teachers regarding the way of planning their courses. Namely, it is not the increased workload in distance learning courses, but the decreased workload in traditional classes that causes the initial discomfort for both students and teachers. Too often face-to-face courses are limited to weekly meetings, and students' learning assessment to the end-of-semester examination. In such a case, the switch to distance education requires from students workload, much heavier than the usual one in traditional classes. This is another reason why the regular training for teaching staff should be considered the key to the high-quality online courses in higher education institutions.

The heavy load of distance education during the COVID-19 pandemic shows that the design and development of online courses (both for distance learning and remote teaching ones) require more microlearning elements. Splitting content into small units helps to avoid cognitive overload (Benedek, and Veszelszki 2016) and, hence the overall impression of the course as "heavy".

It should also be mentioned here that the higher education institutions should be aware of and clearly inform their teachers about the advantages and disadvantages of such forms of distance education as distance learning and remote teaching (Marasi, Jones, and Parker 2020). The two forms are often confused (which can easily be observed even in official documents regarding distance education), and described as distance learning. In the context of distance learning, student engagement techniques as well as the communities of learners should be specially promoted, as the interactions between all learning process participants make it engaging and effective.

\section{Data Availability Statement}

The data that support the findings of this study are available on request from the corresponding author. The data are not publicly available due to privacy or ethical restrictions.

\section{Acknowledgments}

We acknowledge the support of a subsidy from the Ministry of Science and Higher Education for scientific activity 2021.

\section{References}

Aguilera-Hermida A.P., Quiroga-Garza A., Gómez-Mendoza S., Del Río Villanueva C.A., Avolio Alecchi B., Avci D. 2021. Comparison of students' use and acceptance of emergency online learning due to COVID-19 in the USA, Mexico, Peru, and Turkey. Education and Information Technologies. Available at: https://link.springer.com/10.1007/s10639021-10473-8 [Accessed: 20 April 2021].

Al-Azawei, A., Parslow, P., Lundqvist, K. 2016. Barriers and opportunities of e-learning implementation in Iraq: a case of public Universities. The International Review of Research in Open and Distributed Learning 17(5). Available at: http://www.irrodl.org/index.php/irrodl/article/view/2501 [Accessed: 27 April 2021].

Arkorful V., Abaidoo N. 2014. The role of e-learning, the advantages and disadvantages of its adoption in Higher Education. 2(12), pp. 397-410. Available at: https://www.ijern.com [Accessed: 27 April 2021].

Beebe S.A. 1980. The role of nonverbal communication in education: research and theoretical perspectives. Available at: https://www.semanticscholar.org/paper/The-Role-of-Nonverbal-Communication-in-Education\%3ABeebe/6cf632bc9c0753a9e6beb9a2e54a8dd013ce5245 [Accessed: 27 April 2021].

Brinson J.R. 2015. Learning outcome achievement in non-traditional (virtual and remote) versus traditional (hands-on) laboratories: A review of the empirical research. Computers \& Education 87, pp. 218-237. doi: 10.1016/j.compedu.2015.07.003. 
Clark A., Ellis-Thompson A., Gnanapragasam A., Grassian T., Higgins S., Kelly C., Madgwick H., Morgan S., Parry L., Roberts S., Sadler K., Sonnemann J., Stevenson J., Tillotson S., Van Poortvliet M., Zaman M., Coe R., Weidmann B., Coleman R., Kay J. 2020. EEF (2020) - Impact of school closures on the attainment gap. Available at: http://rgdoi.net/10.13140/RG.2.2.32723.81442 [Accessed: 30 June 2020].

Cortera J.E., Escheb S.K., Chassapis C., Ma J., Nickersonb J.V. 2011. Process and learning outcomes from remotely-operated, simulated, and hands-on student laboratories. Computers \& Education 57(3), pp. 2054-2067. doi: 10.1016/j.compedu.2011.04.009.

Croft N., Dalton A., Grant M. 2010. Overcoming isolation in distance learning: Building a learning community through time and space. Journal for Education in the Built Environment 5(1), pp. 27-64. doi: 10.11120/jebe.2010.05010027.

Derouin R.E., Fritzsche B.A., Salas E.. 2005. E-learning in organizations. Journal of Management 31(6), pp. 920-940. doi: $10.1177 / 0149206305279815$.

Engum S.A., Jeffries P., Fisher L. 2003. Intravenous catheter training system: Computer-based education versus traditional learning methods. The American Journal of Surgery 186(1), pp. 67-74. doi: 10.1016/S0002-9610(03)00109-0.

Gill P., Stewart K., Treasure E. 2008. Methods of data collection in qualitative research: interviews and focus groups. British Dental Journal 204(6), pp. 291-295. doi: 10.1038/bdj.2008.192.

Hodges C., Moore S., Lockee B., Trust T., Bond A. 2020. The difference between emergency remote teaching and online learning. Educause review. Available at: https://er.educause.edu/articles/2020/3/the-difference-betweenemergency-remote-teaching-and-online-learning [Accessed: 27 April 2021].

Hong J-C., Lee Y-F., Ye J-H. 2021. Procrastination predicts online self-regulated learning and online learning ineffectiveness during the coronavirus lockdown. Personality and Individual Differences 174, p. 110673. doi: 10.1016/j.paid.2021.110673.

Benedek A., Veszelszki A.. 2016. Micro-content generation framework as a learning innovation. In: In the Beginning was the Image: The Omnipresence of Pictures. Time, Truth, Tradition. Series: Visual Learning. Frankfurt am Main, Bern, Bruxelles, New York, Oxford, Warszawa, Wien. doi: 10.3726/b10396.

Ilie V. 2019. Traditional learning versus e-learning. The European Proceedings of Social \& Behavioural Sciences. EDU WORLD 2018, The 8th International Conference Future Academy. doi: 10.15405/epsbs.2019.08.03.146.

Krishnamurthy S. 2020. The future of business education: A commentary in the shadow of the COVID-19 pandemic. Journal of Business Research 117, pp. 1-5. doi: 10.1016/j.jbusres.2020.05.034.

Marasi S., Jones B., Parker J.M. 2020. Faculty satisfaction with online teaching: a comprehensive study with American faculty. Studies in Higher Education, doi: 10.1080/03075079.2020.1767050.

Means B., Bakia M., Murphy R. 2014. Learning online. What research tells us about whether, when and how. 1st ed., New York, Routledge.

Michinov N., Brunot S., Le Bohec O., Juhel J., Delaval M. 2011. Procrastination, participation, and performance in online learning environments. Computers \& Education 56(1), pp. 243-252. doi: 10.1016/j.compedu.2010.07.025.

Morales-Menendez R., Ramírez-Mendoza R.A., Vallejo Guevara A.Jr. 2019. Virtual/Remote labs for automation teaching: a Cost effective approach. IFAC-PapersOnLine 52(9), pp. 266-271. doi: 10.1016/j.ifacol.2019.08.219.

Olson T., Wisher R.A. 2002. The effectiveness of web-based instruction: An initial inquiry. The International Review of Research in Open and Distributed Learning 3(2). Available at: http://www.irrodl.org/index.php/irrodl/article/view/103 [Accessed: 27 April 2021].

Palvia S., Aeron P., Gupta P., Mahapatra D., Parida R., Rosner R., Sindhi S. 2018. Online education: Worldwide status, challenges, trends, and implications. Journal of Global Information Technology Management 21(4), pp. 233-241. doi: 10.1080/1097198X.2018.1542262.

Suanpang P., Petocz P., Walter K. 2004. Student attitudes to learning business statistics: Comparison of online and traditional methods. Journal of Educational Technology \& Society 7(3), pp. 9-20.

Sinclair P., Kable A., Levett-Jones T. 2015. The effectiveness of internet-based e-learning on clinician behavior and patient outcomes: a systematic review protocol: JBI Database of Systematic Reviews and Implementation Reports 13(1), pp. 52-64. doi: 10.11124/jbisrir-2015-1919.

Stebbings G.K., Mackintosh C., Burden A.M., Sims D. 2021. Improving student progression in distance learning using synchronous webinars. In: Agrati, L. S. et al. eds. Bridges and Mediation in Higher Distance Education. Cham: Springer International Publishing, pp. 315-323. doi: 10.1007/978-3-030-67435-9_24.

Terzi B., Azizoğlu F., Özhan F. 2021. Factors affecting attitudes of nursing students towards distance education during the COVID-19 pandemic: A web-based cross-sectional survey. Perspectives in Psychiatric Care. doi: 10.1111/ppc.12747.

Trelease R.B. 2016. From chalkboard, slides, and paper to e-learning: How computing technologies have transformed anatomical sciences education: How Computing Transformed Anatomy Education. Anatomical Sciences Education 9(6), pp. 583-602. doi: 10.1002/ase.1620.

Viegas C., Pavani A., Lima N., Marques A., Pozzo I., Dobboletta E., Atencia V., Barreto D., Calliari F., Fidalgo A., Lima D., Temporão G., Alvesa G. 2018. Impact of a remote lab on teaching practices and student learning. Computers \& Education 126, pp. 201-216. doi: 10.1016/j.compedu.2018.07.012.

Volet S., Summers M., Thurman J., 2009. High-level co-regulation in collaborative learning: How does it emerge and how is it sustained? Learning and Instruction 19(2), pp. 128-143. doi: 10.1016/j.learninstruc.2008.03.001.

Vu P., Cao V., Vu L., Cepero J., 2014. Factors driving learner success in online professional development. The International Review of Research in Open and Distributed Learning 15(3). Available at:

http://www.irrodl.org/index.php/irrodl/article/view/1714 [Accessed: 27 April 2021]. 
Walsh K., 2018. E-learning in medical education: the potential environmental impact. Education for Primary Care 29(2), pp. 104-106. doi: 10.1080/14739879.2017.1389619.

Whalen B., 2020. Education abroad in a post-COVID-19 world. Inside Higher Ed. Available at:https://www.insidehighered.com/views/2020/04/14/how-COVID-19-will-change-education-abroad-americanstudents-opinion, [Accessed: April 29, 2020].

Zimmerman J., 2020. Coronavirus and the great online-learning experiment. The Chronicle of Higher Education. Available at: https://www.chronicle.com/article/coronavirus-and-the-great-online-learning-experiment/ [Accessed: 27 April 2021].

\section{Appendices}

Questionnaire for teachers (only questions used for the analysis are presented ${ }^{1}$ ):

What is the place of your teaching activity (Faculty, Department)?

Please select your gender:

- Woman

- Man

- Prefer not to say

How long are you using distance learning techniques and methods in your teaching activity? since classes were suspended because of COVID-19 pandemic?

- Since the beginning of the COVID-19 pandemic

- $\quad 1$ year

- 1-2 years

- 3 years or more

Would you like to use distance learning in your teaching practice after resumption of traditional classes?

- Yes

- No

Which factor would you consider decisive at the very moment you have decided to start teaching remotely?

- Better time efficiency

- Better effectiveness of distance teaching

- Willingness to use another form of teaching

- Rector's decision

- Desire to continue teaching during the COVID-19 pandemic other (please define)

- Other

Distance learning strengths are:

\begin{tabular}{|l|l|l|l|l|l|}
\hline & Definitely no & No & Hard to say & Yes & Definitely yes \\
\hline Flexible working hours & & & & & \\
\hline Less face-to-face contact & & & & & \\
\hline Wide availability for people & & & & & \\
\hline $\begin{array}{l}\text { Better accessibility for } \\
\text { with disabilities }\end{array}$ & & & & & \\
\hline $\begin{array}{l}\text { Better accessibility for } \\
\text { foreigners }\end{array}$ & & & & & \\
\hline Better quality & & & & & \\
\hline Other (please define) & & & & \\
\hline
\end{tabular}

Distance learning weaknesses are:

\begin{tabular}{|l|l|l|l|l|l|}
\hline & Definitely no & No & Hard to say & Yes & Definitely yes \\
\hline High workload & & & & & \\
\hline New competencies needed & & & & & \\
\hline
\end{tabular}

\footnotetext{
${ }^{1}$ Questionnaires included more questions concerning various technical aspects of distance learning. The additional part of the research tools is not presented since the data was collected for other purposes of the University of Wrocław.
} 


\begin{tabular}{|l|l|l|l|l|l|}
\hline Less face-to-face contact & & & & & \\
\hline Lower quality & & & & & \\
\hline Other (please define) & & & & & \\
\hline
\end{tabular}

What do you think about the opportunities for wider implementation of distance learning at the University of Wrocław after the COVID-19 pandemic? Please justify your opinion.

Questionnaire for students (only questions used for the analysis are presented):

What is the place of your education (Faculty, Department)?

Please select your gender:

- Woman

- Man

- Prefer not to say

How long do you attend distance learning classes?

- Since the beginning of the COVID-19 pandemic

- $<1$ year

- 1-2 years

- 3 years or more

Did you express a willingness to attend distance learning courses before the COVID19 pandemic?

- Yes

- No

Would you like to participate in distance learning after resumption of traditional classes?

- Yes

- No

Distance learning strengths are:

\begin{tabular}{|l|l|l|l|l|l|}
\hline & Definitely no & No & Hard to say & Yes & Definitely yes \\
\hline Flexible working hours & & & & & \\
\hline Less face-to-face contact & & & & & \\
\hline Wide availability & & & & & \\
\hline $\begin{array}{l}\text { Better accessibility for people } \\
\text { with disabilities }\end{array}$ & & & & & \\
\hline $\begin{array}{l}\text { Better accessibility for } \\
\text { foreigners }\end{array}$ & & & & & \\
\hline Better quality & & & & & \\
\hline Other (please define) & & & & & \\
\hline
\end{tabular}

Distance learning weaknesses are:

\begin{tabular}{|l|l|l|l|l|l|}
\hline & Definitely no & No & Hard to say & Yes & Definitely yes \\
\hline High workload & & & & & \\
\hline New competencies needed & & & & & \\
\hline Less face-to-face contact & & & & & \\
\hline Lower quality & & & & & \\
\hline Other (please define) & & & & & \\
\hline
\end{tabular}

What do you think about the opportunities for wider implementation of distance learning at the University of Wrocław after the COVID-19 pandemic? Please justify your opinion. 